Canadian Journal of Family and Youth, 13(2), 2021, pp. 185-189

ISSN 1718-9748(C) University of Alberta

http://ejournals,library,ualberta.ca/index/php/cjfy

\title{
Lockman, Darcy. (2019). All the Rage: Mothers, Fathers, and the Myth of Equal Partnership. New York: Harper Collins Publishers.
}

Reviewed by: Nicole Paltzat, MacEwan University

Darcy Lockman’s book, “All the Rage: Mothers, Fathers, and the Myth of Equal Partnership”, discusses the inequalities often found within modern households and the accompanying consequences. Despite the increase of women in the workforce over recent years, there has yet to be an accompanying decrease of women's roles in the home. Lockman supports her findings with an array of studies and research, ranging from time-use studies and Facebook group chats, to research on marmoset monkeys (p. 83). Common debates and defences for modern day inequality are brought up, with Lockman providing credible evidence to the contrary. She highlights that there is an unequal weight on the woman of the household, which is much less apparent in the lives of men. This book focuses on the ideologies and beliefs behind these biases, as well as why equality in the home and marriages has yet to be achieved.

As women continue to move up the corporate ladder their role in the home does not change. Even in relationships with unemployed fathers and employed mothers, managerial task levels are unproportionate, with the woman doing much more (p. 34). The arrival of children is proven to increase the severity of household inequality, as many women's groups detailed in the book have shown that fathers are typically not given the primary caregiver role due to their blindness to what 
the role entails. A trend apparent in many homes is the mother doing things herself, on the basis that her husband is unlikely to think of doing it. When they speak out and assign a household task to them, many women are left disappointed by the outcome. It is not uncommon for things to be done improperly or not at all when they are passed to someone who is not the primary caregiver. Micromanaging and nagging are not preferences for anyone involved, but through personal anecdotes shared it is clear why these are seen as the default. Until there is a change in conversation to get to the root of the problem, surface level actions such as those will never truly have the desired effect. For fathers to take an active role they need to be aware of what needs to be done, not simply preparing food or putting the kids to bed, but also keeping up with school emails, appointments, and encouraging healthy conversations and bonding with their kids. Many pieces of parenting are overlooked on a day-to-day basis when one is never faced with being in charge of it. A deeper conversation needs to be had about entitlement and consideration, and the difference between these across genders.

Shared experiences of modern moms are commonly touched on in this book, often through Facebook discussions or stories of friends. Lockman makes it apparent that although many women are discontent with the setup of responsibilities in the home, they are also the ones quickest to brush it off and say "things could be worse, like in the past". This kind of thinking is a great detriment, accepting things just because it used to be worse is not a way which change can be made and maintained. Many women find themselves defending their husbands, arguing "it's not that bad. He doesn't beat me. He doesn't drink excessively" (p. 22), showing that for some, the bar of expectations is strikingly low. This book highlights the depressing truth about many relationships, 
problems are swept to the side on the basis that there are worse possibilities than the ones currently being faced.

Another strong force holding damaged relationships together is the fear of an unstable home environment and upbringing for children. Many parents choose to continue a life of arguing over a life without the typical mother-father household. In regards to same sex couples, the book focuses mainly on opposite sex couples, but discrepancies are still apparent. Men are not the only ones to blame for inequality, as women share many of the same beliefs and rhetoric. Family psychologists have stated that "women's lack of entitlement is partially responsible for the uneven distribution of family labor" (p. 269). It is clear that not only the individuals in the marriage suffer, but their children and the greater society do too. To highlight the effects of inequality in the home on the economy and society, Lockman provides "a 2015 report from think tank McKinsey Global Institute estimated that the world economy would be $\$ 28.4$ trillion (or 26 percent) richer by 2025 if the gender gaps in labor force participation and productivity were bridged" (p. 45). What occurs within a household does not stay there. The perspectives being fostered in the home have a large impact on the areas outside of it.

A popular debate against the need for men to handle a larger role in the household is the belief that women are just born better suited for parenting, and are the only ones with maternal instinct. Lockman provides many sources of evidence arguing that the commonly found differences between fathers and mothers are not based purely on the nature of the sex, but actually due to the differences in upbringings. Additionally, our current actions enforce our roles, 
so even if an individual was raised with the intention of growing up to be a mother, Lockman writes, "brains are not so much hardwired as constantly rewiring themselves in response to realtime experience" (p. 90). By either actively taking on or neglecting the tasks of the parent, the individual is hardwiring their brain to respond similarly in the future thus enforcing their role.

Part of the issue is the willingness of people to put men on a pedestal when they help with the children or home, as if they are doing a favor rather than a responsibility. There is a reason motherhood is often referred to as a thankless job, it is simply expected that the mother does it. No matter the woman's career, salary, health, or beliefs, the weight of home life usually rests on her shoulders. It is not second guessed whether a man should be able to come home from a long work day and relax on the couch, but working moms are met with judgement and guilt if they do the same. As Lockman states, “a male partner's contribution to child care is the most important factor predicting relationship conflict and mothers' satisfaction" (p. 41). The problem at hand is not simply that women are left with doing more than their husband, but rather the resentment and tension which build from this.

An array of audiences would benefit from this book, from sociologists to the everyday mothers and fathers around us. It is an especially useful resource in understanding the reasoning behind the lack of progress in certain aspects of our modern lives, while also providing insight into the achievements made over the years. This book is easy to approach and understand, filled with statistics and personal anecdotes. I think it is a great starting point for anyone who cares to learn more about parent dynamics and the consistent power imbalances within them. The writing is clear and simple enough that beginners to the subject would easily follow along. The simpli- 
city allows for a greater audience, and a more personal connection. The book reminds its audience that although great strides have been made in gender equality, there are still behaviours that have not caught up, summed up by researchers stating change has been "more in 'the culture of fatherhood' than the actual behaviour" (p. 25). The book provides great perspectives and arguments, tying in both biological science and social sciences. Overall, an important read for sociologists and psychologists, especially individuals specializing in marriage and child care. 